\title{
O papelão revisitado: experiências pedagógicas a partir de editoras cartoneras
}

\author{
El cartón revisitado: experiencias pedagógicas a partir de editoriales \\ cartoneras \\ The cardboard revisited: pedagogical experiences from cardboard \\ publishing
}

Camila Dalcin ${ }^{1}$

\begin{abstract}
Resumo
Entender como podem se dar relações pedagógicas entre a criação, editoração e a produção de literatura através da autonomia do educando por um caminho artesanal em plena era tecnológica justifica este trabalho. Para isso analiso a produção de cartoneras em sala de aula. As editoras cartoneras que ganharam a América Latina desde o início deste século tem como característica as produções de livros a partir dos cartóns (papelão), comprados de cartoneros (catadores) com a publicação de textos literários cedidos por escritores já legitimados no mercado literário, assim como de novos escritores que ocupam as margens sejam econômicas ou territoriais, além da reedição de textos literários que nem sempre cruzavam suas fronteiras de origem. O movimento não é ingênuo, pois aposta na ousadia e na transgressão cultural, muitas vezes, questionando os espaços hegemônicos de produção literária. Transportar esse movimento para dentro da sala de aula e pensá-lo como recurso pedagógico incitando a produção pelos educandos, tornando-os autores, editores e confeccionadores de seus próprios livros pode ser um recurso interessante no que tange a reaproximação dos estudantes com a literatura.

Palavras-chave: editoras cartoneras, escrita criativa; autonomia
\end{abstract}

\section{Resumen}

Entender cómo pueden darse relaciones pedagógicas entre la creación, la publicación y la producción de literatura a través de la autonomía del educando por un camino artesanal en plena era tecnológica justifica este trabajo. Para ello analizo la producción de cartoneras en el aula. Las editoriales cartoneras que ganaron América Latina desde el inicio de este siglo tienen como característica las producciones de libros a partir de los cartones (cartón), comprados de cartoneros (recolectores) con la publicación de textos literarios cedidos por escritores ya legitimados en el mercado literario, así como de nuevos escritores que ocupan los márgenes son económicos o territoriales, además de la reedición de textos literarios que no siempre cruzaban sus fronteras de origen. El movimiento no es ingenuo, pues apuesta en la osadía y en la transgresión cultural, muchas veces, cuestionando los espacios hegemónicos de producción literaria. Transportar ese movimiento hacia dentro del aula y pensarlo como recurso pedagógico incitando la producción por los educandos, haciéndolos autores, editores y confeccionadores de sus propios libros puede ser un recurso interesante en lo que se refiere a la aproximación de los estudiantes con la literatura.

Palabras clave: editoriales cartoneras, escritura creativa; autonomía

\begin{abstract}
Understanding how pedagogical relations can be established between creation, publishing and production of literature through the autonomy of the student through a craft path in the technological era justifies this article. To this end, I analyze the production of cartoneras in the classroom. The cardboard publishers that have won Latin America since the beginning of this century have the production of books from cartón (cardboard), bought from cartoneros (garbage collectors) with the publication of literary texts provided by already legitimized
\end{abstract}

\footnotetext{
${ }^{1}$ Mestre em Estudos Literários pela UFSM; professora-formadora na Especialização em Ensino de Filosofia EAD UFPEL; Pelotas, Rio Grande do Sul, Brasil; camiladalc@gmail.com
} 
writers in the literary market, as well as as new writers who occupy the economic or territorial margins, and as the reprint of literary texts that did not always cross their original borders. The movement is not naive, because it bets on boldness and cultural transgression, often questioning the hegemonic spaces of literary production. Carrying this movement into the classroom and thinking it as a pedagogical resource, inciting production by the students, making them authors, editors and makers of their own books can be an interesting resource for them as a rapprochement with literature.

Keywords: Cartoneras publishers, creative writing; autonomy

\section{Introdução}

No continente Latino-Americano a resistência é o modo operante da população. Por aqui se resiste à dominação de mãos gananciosas, à miséria imposta por uma desigualdade criada, à violência como estigma. Diante disso as armas da resistência são muitas, porém nestas páginas escolho contar a história de quem elegeu o cartón ${ }^{2}$ e a literatura para lutar, não só para resistir em tempos de crise, mas também reexistir enquanto fenômeno artístico.

Sob a ótica da resistência, interessa entender como o processo de editoração cartonera pode refletir em práticas pedagógicas que refletem a autonomia do educando através da criação, editoração e a produção de literatura por um caminho artesanal em plena era tecnológica. Para isso analiso a produção de cartoneras em sala de aula como recurso pedagógico que incita a produção pelos educandos, tornando-os autores, editores e confeccionadores de seus próprios livros e como isso pode ser um recurso interessante no que tange à reaproximação dos estudantes com a literatura

Neste trabalho proponho como relato de experiência a prática pedagógica da disciplina de Língua Portuguesa e Literatura Brasileira que levou educandos do Ensino Médio Técnico no Instituto Federal Sul- rio-grandense a lançarem seus próprios livros cartoneros.

\section{Editoras Cartoneras: o papelão revisitado}

O que caracteriza uma editora cartonera são as produções de livros a partir dos cartóns, comprados de cartoneros (catadores ${ }^{3}$ ) com a publicação de textos literários cedidos

\footnotetext{
2 Papelão em espanhol

3 É um trabalhador urbano que recolhe os resíduos sólidos recicláveis, tais como papelão, alumínio, vidro e outros. A atividade da catação de papel, papelão e outros materiais recicláveis, envolve toda a família quer seja no trabalho de rua quer seja no local de armazenamento dos resíduos recicláveis. Entretanto, não se trata só de moradores de rua (a maioria dessa população sobrevive dessa ocupação conforme censo de SP de 11 mil pessoas); mas também de pessoas inseridas em condições de pobreza vivendo a maioria em ocupações irregulares, em assentamentos organizados pelo Governo ou mesmo em lotes adquiridos. São famílias inteiras envolvidas na catação de materiais e muitas vezes os locais onde moram dificultam o acesso a equipamentos sociais como postos de saúde e escolas. Em muitos casos as crianças e os adolescentes estão fora da escola e não têm tido o acesso à saúde como é de direito. (http://www.mma.gov.br/cidades-sustentaveis/residuossolidos/catadores-de-materiais-reciclaveis )
} 
por escritores já legitimados no mercado literário, assim como de novos escritores que ocupam as margens sejam econômicas ou territoriais , além da reedição de textos literários que nem sempre cruzavam suas fronteiras de origem. $\mathrm{O}$ movimento não é ingênuo, pois aposta na ousadia e na transgressão cultural, muitas vezes, questionando os espaços hegemônicos de produção literária.

As editoras cartoneras começam ao sul do sul. Um bairro periférico da cidade de Buenos Aires, Argentina, é o primeiro terreno desta fértil possibilidade literária, a Eloúsa Cartonera, criada em 2003, é um projeto —-social, cultural e comunitario, sem fins lucrativos, que publicou até o momento mais de 200 títulos, incluindo poesias, contos, peças teatrais, ensaios, literatura infantil, textos inéditos e traduções, desde escritores desconhecidos até consagrados. Composta por um grupo de pessoas que confeccionam livros a partir de material reciclado, feitos à mão, com capas de papelão, pintados com tinta guache, o miolo editado em folhas A4, multiplicados através das fotocópias de textos literários, encardenados (costurados ou grampeados) e comercializados, com custos mais baratos que os convencionais, por todos os envolvidos no processo. Tal atividade tornou possível a formação de um processo editorial coletivo, descentralizado. Assim surgiu uma cooperativa cartonera que rompeu com a hierarquia produtiva em relação ao modelo tradicional de produção de livros. A função desta editora é a de publicar uma cópia permitida pelo autor e difundir literatura de maneira democrática e acessível.

Las ediciones de una obra determinada dependen de los recursos con los que cuenten los editores y de la demanda prevista; en general se trata de tiradas pequeñas y espaciadas en el tiempo. Los ejemplares suelen ser distintos entre sí - por lo menos en su cubierta- y, en consecuencia, podría decirse que cada libro es "único". Lo más habitual es que sus catálogos sean modestos, y que los libros se vendan a precios muy bajos, incluso irrisorios. Los canales de distribución pueden ser muy variados e incluir espacios comerciales como librerías y oficiales como ferias del libro, o basarse en el contacto personal, el boca a boca, los blogs y las redes sociales, y las propuestas "alternativas" (venta callejera o en comercios de barrio, ferias independientes, consigna de libros en instituciones, etc.). (CIVALLERO, 2015, pg 5)

A exemplo de Eloísa, hoje mais de 200 editoras cartoneras se proliferarem por toda continente latino americano, chegando também em países europeus e africanos. Aqui nos interessa, mesmo que de forma incipiente, discutir o que as editoras cartoneras refletem sobre o contemporâneo? Para tanto colocamos em discussão autores que olham criticamente para o contemporâneo.

Começamos com um ponto significativo dado por Raymond Willians, que avalia este momento histórico através do duplo movimento da nossa economia e da nossa sociedade: de 
um lado, os processos e avanços tecnológicos; de outro, as profundas desigualdades sociais, de tal maneira que se tem a forte sensação de que o pós-modernismo chegou muito antes do fim do modernismo em países periféricos. De acordo com a leitura de Raymond Willians:

\begin{abstract}
Isso se traduz em traços formais, em mudanças de estilo e em incorporação de conteúdos à literatura, que funcionam como antenas das mudanças sociais ainda em curso. São traços emergentes convivendo com resíduos de outro tipo de produção cultural e literária, característica de estágios anteriores, estando assim sempre presentes soluções diversas, traduzindo as contradições que operam na sociedade. (WILLIANS, 2002, pg.47)
\end{abstract}

Por isso, o que se observa é a emergência e a consolidação de outra forma de representar, de se construir o universo da literatura. A incorporação de outras vozes - que culmina no hibridismo - contestaria as formas hegemônicas e as autoridades sócio-políticas e literárias. Por isso para Nizia Villaça (1996), a multiplicidade de perspectivas e o hibridismo são os motores que questionam os paradigmas impostos. Em Sujeito e Ficção: paradoxos do pós-moderno, Villaça procura entender, através da perspectiva do sujeito, o lugar e o tempo do pós-modernismo, passando por suas origens, pelos teóricos que o pensam e pelas principais características que compõem a contemporaneidade, sobretudo no território das manifestações artístico-culturais. Dessa forma, ela reconhece o momento atual como sendo o da:

(...) problematização, mais do que da negação, de todos os modelos e parâmetros. Opção pela multiplicidade de paradigmas, pelos paradoxos, pelas micro-abordagens em substituição à ortodoxia, aos macrodiagnósticos, às totalizações provenientes do desejo característico do racionalismo que orientou predominantemente o paradigma do saber no ocidente. (VILLAÇA, 1996, p.7)

A autora aposta na multiplicidade como chave de leitura para este período sóciohistórico e, principalmente, para suas manifestações estéticas, e explora isso através da metáfora do altar, segundo a qual a centralidade de um único santo redentor sucumbe diante de "nichos laterais que se enchem de santos, fiéis, promessas e crenças" (VILLAÇA, 1996, p.28). Apagam-se, dessa forma, as dicotomias modernas tais como natureza/cultura, arte/nãoarte, alta cultura/baixa cultura, literário/não literário.

A metáfora do altar está diretamente relacionada ao fim das dicotomias e vai refletir na multiplicidade, elemento central ao que a autora entende por pós-modernidade, desde o fim de um centro legitimador até a possibilidade de escrever fora dos espaços hegemônicos. Segundo Villaça, os discursos redentores e universais são colocados de lado, para que entre em cena a complexidade da diversidade, do hibridismo e a convivência com a diferença: "quando se 
rediscutem os espaços, os tempos, a história, a subjetividade, com preocupações genealógicas, do que não é dado nem natural, mas construído" (VILLAÇA, 1996, p.29).

Entendemos, então, que as editoras cartoneras subvertem a lógica dicotômica, sendo um terreno fértil para o hibridismo defendido pela autora. Podemos entender as cartoneras como um ponto de fuga surgidos a partir das fissuras geradas pelo sistema neoliberal, e nesta fuga pretendem democratizar o acesso ao campo literário, mediante a autogestão, gerando assim, uma energia distinta e a possibilidade de formas alternativas de produção de objetos culturais.

El eje de toda esta actividad es el libro, un bien cultural tremendamente simbólico que el actual sistema imperante ha convertido no solo en un producto de consumo más - encadenado por las leyes del mercado- sino en un instrumento de manipulación, de elaboración, articulación y reproducción de relatos y hegemonías. La edición de libros "cartoneros" vendría a redefinir categorías como "autor", "libro", "publicación" y "lector", a alterar la actual relación entre ellos, y a diseñar nuevas políticas de autoría, edición, distribución y utilización, basadas en valores distintos a los del modelo imperante. (CIVALLERO, 2015, pg 11)

Lemos as editoras cartoneras como movimentos que refletem o contemporâneo através do hibridismo de suas formas e, sobretudo, da transgressão do campo literário, colocando em cheque valores já consolidados. Não há regras nas páginas envolvidas pelo cartón.

\section{Cartonagem na sala de aula: (re)significando o cânone}

Como professora de Literatura, sempre me perguntei o que fazer para que os educandos, envoltos em aparatos tecnológicos, pudessem se divertir com um livro tanto quanto se divertem com seus celulares. Ouvi atentamente as críticas que os estudantes fazem sobre não se identificarem com as obras trabalhadas na escola, como não se sentem representados, muitas vezes distantes da linguagem usada em romances de época, por exemplo. Não entendiam porque eram obrigados a ler algo tão remoto nos seus imaginários do que é uma ficção. A distância também acontecia quando imaginavam os autores, figuras pra eles tão remotas quantos suas narrativas.

A partir de relatos dos educandos compartilhados em diferentes turmas do segundo semestre do Ensino Médio Técnico do Instituto Federal Sul-rio-grandense, construímos experiências de leitura e escrita, que resultaram em publicações cartoneras. O caminho até os livros, passou por exercícios de escrita criativa, editoração, ilustração, produção das capas e lançamento, protagonizados pelos educandos em todas as etapas. $\mathrm{O}$ objetivo era de que, na medida do possível, revertêssemos esta distância diagnosticada, através da tomada de posição do educando como autor de narrativas. 
Aproveitando o conteúdo programático - verbos e gênero textual narrativa- pensamos um projeto que passou por quatro etapas, resultando em quatro livros cartoneros criados pelos estudantes. A primeira delas foi um jogo de roda: no início era o verbo ${ }^{4}$, no qual a turma em círculo (16 alunos) falaria o primeiro verbo que pensassem (verbos no infinitivo); a cada rodada uma lista surgia.

Na segunda etapa, a turma já dividida em grupos criou narrativas que usassem os verbos de uma das listas. Muitas histórias brotaram, foram quatro narrativas, cada uma seguia de forma que usassem os verbos dispostos nas listas. Durante a etapa de criação das narrativas, tivemos momentos importantes: o primeiro, foi o processo criativo, da explosão de ideias, atividade em aula, na qual os grupos pensaram os argumentos para suas histórias. No segundo momento, com o fio condutor estabelecido, começa o processo de construção narrativa: compor enredo, personagens, tempo, espaço, ponto de vista narrativo, vozes do discurso. Durante a produção textual foi necessário a pesquisa e estudo sobre os modos e os tempos verbais, e o fizeram a partir das demandas de suas narrativas, a partir das ações demandadas de seus personagens ou de seus narradores.

Narrativas criadas, passou-se pelo processo de editoração e ilustração das histórias, este processo foi bastante interessante porque lidamos com outras modalidades textuais, as imagens que se deram por colagem ou por ilustrações criadas pelos próprios autores. Durante essa etapa, discutimos as possibilidades de se contar a história para além das palavras, e como imagens e ilustrações também constituíam a narrativa, brincando com as possibilidades semióticas do trabalho multimodal. Assim como foi a confecção das capas a partir de papelões recolhidos nos arredores do Instituto, nos quais os autores confeccionaram seus livros e pintaram suas capas. Finalizamos o processo com o lançamento dos livros no hall da escola.

\section{Considerações Finais}

O processo de criação das narrativas e a transformação em livros, materializando o lugar de aluno-autor, possibilitou que os estudantes criassem histórias que, de alguma medida, representassem o que entendem como literatura, que se reconhecessem no fazer literário e partir disso reivindicassem suas narrativas, ressignificando o valor literário. Compactuando com as reflexões de Montezuma, nas quais defende o uso da cartonagem como um recurso importante para a formação crítica do educando:

\footnotetext{
${ }^{4}$ Jogo de palavras no qual os estudantes, em roda, diziam os verbos que vinham a mente.
} 
Una cartonera es el pretexto para ejercer el permiso de cuestionar. Inclusive, más significativo que leer autores o autoras no canónicas es la efectiva oportunidad de poder cuestionar, criticar y generar el diálogo. Este hecho ya es un giro contundente que evidencia un cambio en la enseñanza de Literatura en la escuela. Evidentemente, la construcción de una postura y el desarrollo de habilidades de interpretación en los y las estudiantes requiere de un entrenamiento sostenido en habilidades, sino señalar las posibilidades y limitaciones que ofrece una cartonera como espacio de resistencia literaria dentro de la escuela. (MONTEZUMA, 2016, p.12)

No lugar de autor o educando pode questionar os valores impostos sobre o que é literatura e quem pode fazer literatura? Se empoderando do processo de criação, com códigos que comuniquem suas concepções de literatura. Questionando os valores que impõe cânones e que legitimam o que é ou não literatura. O processo de produção cartonera durou oito semanas, nas quais percebi muitos educandos se reconhecendo nos seus processos criativos, leitores assíduos, editores, ilustradores e, o que é mais caro nesse trajeto, autores de suas próprias narrativas.

\section{Referências}

Bilbija, Ksenija. Borrón y cuento nuevo : las editoriales cartoneras latinoamericanas”. Nueva Sociedad no. 230. Nov/Dic 2010, pp. 95-114

ANZALDUA, G. Como domar uma língua selvagem. Cadernos de Letras da UFF, 297-309, 2009.

CANDAU, Vera, M, F, OLIVEIRA, Luiz, F, Pedagogia decolonial e educação antirracial e intercultural no Brasil, Educação em Revista, Belo Horizonte, v.26, n.0, p.15-40, abr. 2010.

CELIS Carbajal, Paloma. Akademia Cartonera: Un ABC de las editoriales cartoneras en América Latina. Madison, Wisconsin: Universidad de Madison Wisconsin, 2009.

CIVALLERO, Edgardo. Libros cartoneros Olvidos y possibilidades. Distribuido como preprint bajo licencia de creative commons by-nc-nc 4.02015 http://bibliotecario.blogspot.pe/search/label/Libros\%20cartoneros

FREIRE, Paulo. Pedagogia da autonomia. Saberes necessários à prática educativa. 7. ed. São

Paulo: Paz e Terra, 1996.

GOMES, Luiz Fernando. Hipertexto no cotidiano escolar. São Paulo: Cortez, 2011.

Martínez Arranz, Beatriz ¡Fuerza Cartonera! Un estudio sobre la cultura editorial cartonera y su comunicación Diseño de un plan 2.0 para Aida Cartonera". Tesis. Universidad de Valladolid, 2013 h ttps://uvadoc.uva.es/bitstream/10324/3777/1/TFM-B.57.pd

HOOKS, Bell, Ensinando a transgredir: a educação como prática da liberdade, Tradução de Marcelo Brandão Cipolla, São Paulo: Editora WMF Martins Fontes, 2013.

Linguagem: ensinar novas paisagens/novas linguagens. Revista Estudos Feministas, Florianópolis, v. 16, n. 3, p. 857, set. 2008. ISSN 1806-9584

NOGUERA, Renato. Denegrindo a educação: um ensaio filosófico para uma pedagogia da pluriversalidade. Revista Sul-Americana de Filosofia e Educação - RESAFE, 2012. 
SOUZA, A. L.S. Letramentos da Resistência: poesia, grafite, música, dança: hip hop. 1. ed. São Paulo: Parábola Editorial, 2011. v. 1. 176p.

SOUZA, Ana Lúcia S. JOVINO, Ione S., MUNIZ, Kassandra S., Revista da ABPN - v. 10, Ed. Especial - Caderno Temático: Letramentos de Reexistência. Janeiro de 2018, p.01-11

SZUNDY, P. ; OLIVEIRA, MARIA BERNADETE FERNANDES DE. Práticas de multiletramentos na escola: por uma educação responsiva à contemporaneidade. Bakhtiniana: Revista de Estudos do Discurso, v. 9, p. 184-205, 2014.

ROJO, Roxane. Letramentos múltiplos, escola e inclusão social, São Paulo: Parábola editorial, 2009

; MOURA, Eduardo. Multiletramentos na escola . São Paulo: Parábola editorial, 2012

VILLAÇA, Nizia. Paradoxos do pós-moderno: sujeito e ficção. Rio de Janeiro: Editora UFRJ: 1996.

WILliAMS, Raymond. Tragédia Moderna. Trad. Betina Bischof. São Paulo: Cosacnaify, 2002. 